\title{
Transfer of Conditionability Between Planaria Through DNA and RNA
}

\author{
Cecilia Schiavoni', Jessica Genter ${ }^{1}$, and Dr. Allison Mayle ${ }^{2}$ \\ ${ }^{1}$ Marymount School of New York, NY, USA \\ 2DNA Learning Center, Cold Spring Harbor, NY, USA
}

\section{ABSTRACT}

This experiment examined whether the transfer of DNA or RNA from conditioned planaria could make the recipients more susceptible to similar conditioning. It has been shown in prior experiments that cephalization is not necessary for memory retention in planaria, so there must be another, non-neural mechanism for memory. Thus, changes in DNA or RNA may be responsible for memory retention and introducing these changes to naive planaria could transfer the "memory" of the conditioned donor. This study included 3 groups of 11 planaria: the control group, the DNA receival group, and the RNA receival group. After the control group was conditioned, each planarian's RNA and DNA were extracted and given to its genetically identical counterparts in the DNA and RNA receival groups. The number of trials it took to condition the planaria in each group was measured and compared to see if the transfer of RNA or DNA made the recipients more easily conditional than the control donor group. The results show that the transfer of RNA and DNA made insignificant changes to the conditionability of recipients. However, further research may be able to identify the location of memory-bearing molecules, which, if applied to experiments similar to this one, would ensure that the planaria received a high enough concentration of genetic material for any changes present to have a significant effect.

\section{Introduction}

Planaria are considered to have a primitive brain because of their primitive synaptic nervous system with cranial ganglia, organized to suggest that they have the capacity for learning (Abbot \& Wong, 2008, p. 160). Planaria are the first organisms to have a true synaptic nervous system, definite encephalization, and bilateral symmetry, which are traits that can be traced to higher species (Mueller, 2002, p. 1). These qualities make planaria a good candidate for study of basic memory and learning processes.

Planaria have been shown to have the capacity for learning and conditioning, and this experiment utilizes associative learning, specifically classical conditioning. In associative learning, the brain relates two events with one response as a unit (Hawkins \& Byrne, 2015, p. 1). Classical conditioning, a type of association, enhances the response to stimulation of one pathway with activity in another (Hawkins \& Byrne, 2015, pp. 1-2). Typically, in classical conditioning, a weak conditioned stimulus (CS) becomes more effective in producing a behavioral response when paired with a strong unconditioned stimulus (UCS) (Hawkins \& Byrne, 2015, pp. 1-2). When learning has occurred, the planaria anticipate their response to the UCS after sensing the CS (Mueller, 2002, p. 1).

The original idea in memory research was that the engram, a hypothetical biophysical or biochemical change occurring when a memory was created, was stored in the synapse (Carney, 2018, p. 1). However, experiments on planaria have shown that memory and learned responses are not stored exclusively in the cranial ganglia because when a planarian is conditioned and then cut transversely, both regenerated sections have equal retention of conditioned behavior, although the tail sections do not contain the original cranial ganglia (Mueller, 2002; Ragland \& Ragland, 1965; Shomrat \& Levin, 2013; Smalheiser et al., 2001; Walker, 1966; Walker \& Milton, 1966). Since both segments equally retain the memory of the original planarian, it suggests that cephalization, or the presence of the sense organs 
and brain in the head region, is not necessary for memory retention and that memory is not a purely neurological mechanism (Mueller, 2002, pp. 1-2). A non-neural mechanism, possibly molecular, may occur throughout the body to record information, explaining this phenomenon (Mueller, 2002, p.14).

Many hypotheses for the location and mechanism of memory include genetic material like RNA. Modern discoveries such as epigenetic modification (in many cell types besides the central nervous system (CNS)) and RNAi support the plausibility of memory traces being encoded and stored in remaining tissues after head removal (Shomrat \& Levin, 2013, p. 3807). Mueller mentions that memory may involve RNA modification, specifically in the neoblasts of planaria, which are the un-differentiated cells containing a high volume of genetic material responsible for regeneration in planaria (Mueller, 2002, p. 14).

It is likely that epigenetic pathways, responsible for determining patterns of self-organization of neural and non-neural (but electrically communicating) cells, also regulate both brain remodeling and regeneration (Shomrat \& Levin, 2013, p. 3807). It is also possible that only a rough correlate of memory exists in the neoblasts, and a brief reexposure to conditioning is necessary to trigger its effects in the planarian's behavior (Shomrat \& Levin, 2013, p. 3807). The information stored outside of the brain must then be implanted on the new brain after regeneration of the top half (Shomrat \& Levin, 2013, p. 3800). The brain is still the main drive of the planarian's behavior since planaria regenerated from the bottom half of conditioned planaria do not show the learned behavior until after the brain has been regenerated (Shomrat \& Levin, 2013, p. 3807).

In experiments during the $1960 \mathrm{~s}$, James V. McConnell found that by injecting chemical extracts of conditioned planaria into naïve planaria, or by feeding them conditioned planaria (since planaria are cannibals), they could exhibit conditioned responses with no training (Smalheiser et al., 2001, p. 216). More contemporary studies have opposed the idea that literal memories are transferred. It is more likely that the increased responsivity of cannibal planaria may be due to an intensified sensitivity to experimental variables as a consequence of ingesting shocked tissues (Walker \& Milton, 1966, p. 293).

In a different experiment, Walker tested to see if RNA increases sensitivity to the stimulus or if the actual association between the stimulus and response is passed on (Walker, 1966). He found that cannibalism enhances sensitization but does not pass memories (Walker, 1966). In his experiment, RNA was transferred between two different species of planaria to see if RNA from an easily trained species, D. dorotocephala, could make a less easily conditionable species, D. tigrina, subsequently conditionable. The results showed that some factor from the conditioning of D. dorotocephala was transferable through cannibalism to D. tigrina because they became more easily conditionable compared to D. tigrina that did not receive any RNA (Walker, 1966, p. 118). Another experiment by Ragland and Ragland showed similar results: conditioning in planaria not previously able to be conditioned was mediated by a transferable factor in the RNA from trained conditionable planaria (Ragland \& Ragland, 1965, p. 118).

There have been many experiments on conditioning and memory in Aplysia that explore RNA transfer. In Aplysia, Bédécarrats et al. as well as Carney found that RNA from the CNS of sensitized individuals induces behavioral sensitization when injected into the CNS of naive Aplysia, suggesting that the nucleus is a cellular location for memory storage (Bédécarrats et al., 2018; Carney, 2018). RNA injection causes DNA methylation of existing genes, so Bédécarrats et al. proposed that specifically non-coding RNAs, which mediate epigenetic changes, are responsible for the behavioral results (Bédécarrats et al., 2018, pp. 1, 8; Carney, 2018, p. 2). The findings support the idea that RNA generates a priming component of the engram for long-term sensitization, and that RNA transfer induces epigenetic, non-synaptic changes, which mediate behavioral effects resembling the effect of conditioning in trained animals (Carney, 2018, p. 2). These findings also suggest that more concrete results may be possible if certain parts of genetic material are isolated and concentrated.

Given this information, this study tries to determine whether the transfer of DNA or RNA from classically conditioned planaria to naive planaria will make the recipient planaria more easily conditional. 


\section{Materials and Methods}

\section{Basic Planaria Care}

Dugesia dorotocephala planaria were obtained from Flinn Scientific, Inc. Eleven of the largest and healthiest planaria were separated from the general population and stored individually. The planaria were kept in petri dishes filled with bottled spring water and stored in a dark, room temperature area. They were fed hard-boiled egg yolk twice a week, and their containers were cleaned less than six hours later to remove the residual food and waste.

\section{Classic Conditioning}

Before training, the 11 selected planaria were cut transversely and allowed 13 days to regenerate in separate containers. Each original planarian, after being cut, was separated randomly between the experimental conditioning group (ECG) and the experimental receival group (ERG). 13 days later, the ERG was cut transversely again to randomly separate the group into the DNA receival group (ERG DNA) and the RNA receival group (ERG RNA). This process guaranteed that each of the 33 planaria had a genetically identical counterpart in the other two groups. Later, when the DNA and RNA was transferred, the three corresponding groups also ensured that any changes in the ERG groups after receiving genetic material from their genetically identical counterpart were due to changes in the genetic material after the conditioning of the ECG and not any differences that would have been present in the DNA between unrelated planaria.

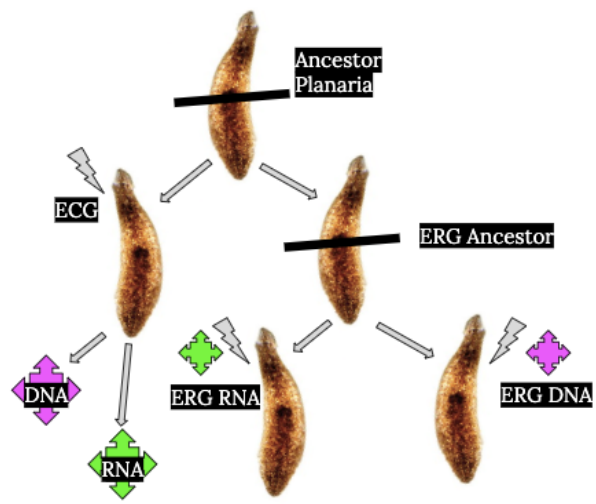

Figure 1. Illustration of the division of a planarian between the three experimental groups. All planaria resulting from the ancestor planarian are genetically identical. Planaria photo (Black Planaria, n.d).

The 11 planaria in the ECG received conditioning meant to instigate associative learning (on the same day that the ERG was separated). Each individual planarian was placed in the center of a plastic petri dish filled with saltwater in a ratio of $0.1 \mathrm{~g}$ of salt: $200 \mathrm{~mL}$ of water.

The conditioning consisted of shining a concentrated flashlight (CS) on the planarian for 3 seconds and shocking (UCS) the subject by completing a circuit composed of four AA batteries and two wires. One of the wires was permanently in the water, and to complete the circuit, the other wire was temporarily placed in the water. The planarian was shocked briefly, which resulted in a body contraction. The saltwater in the dish was exchanged after every 2 planaria testing rounds. The planarian was considered trained when it anticipated the shock by contracting after the application of the flashlight but before the actual shock was applied in three consecutive runs. 


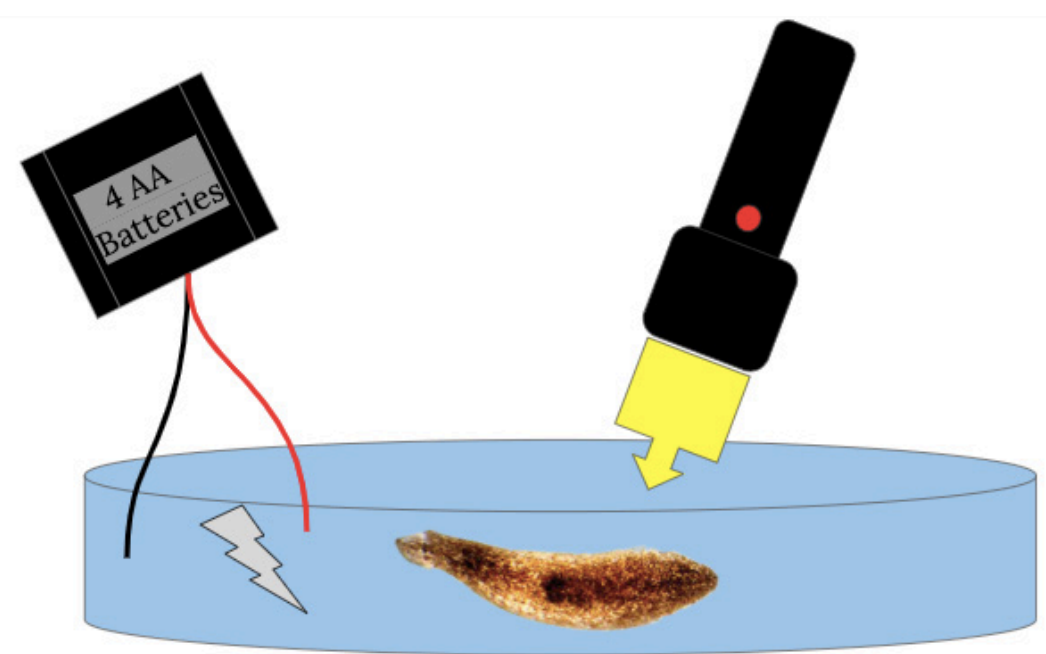

Figure 2. Illustration of a model of the training apparatus used. Planaria photo (Black Planaria, n.d).

\section{Extraction and Introduction of Genetic Material}

The DNA and RNA of the 11 planaria in the ECG were extracted on the same day as conditioning and given to their genetically identical member of the ERGs. The Rapid DNA Isolation Kit was used to extract the genetic material from the ECG planaria. Each trained planarian was crushed into fine particles with $50 \mu \mathrm{l}$ of lysis solution. A 3-mm diameter disc of Whatman No. 1 Chromatography paper was fully submerged in the solution with sterile tweezers for one minute. The chromatography paper was transferred to a fresh microfuge tube with $200 \mu \mathrm{l}$ of wash buffer and soaked for one minute. After that time, a sterile pipette was used to drag the paper to the top of the tube in order to air dry for 2 minutes to evaporate the ethanol. After the disc dried, it was transferred into a fresh microfuge tube with $50 \mu l$ of $\mathrm{TE}$ and frozen. It was left there for four days to allow the ERGs to regenerate.

After four days, the TE solution from each planarian was thawed and split in half, resulting in two microfuge tubes containing $25 \mu \mathrm{l}$ of the TE solution. For the tube being given to the ERG RNA, $5 \mu \mathrm{l}$ of DNAse buffer, $0.5 \mu \mathrm{l}$ of DNAse, and $19.5 \mu \mathrm{l}$ of water was added. For the ERG DNA sample, $0.5 \mu \mathrm{l}$ of RNAse was added. The DNA and RNA solutions were incubated at $37^{\circ} \mathrm{C}$ for 10 minutes.

After incubation, the samples were removed, and 0.05-0.1 g of hard-boiled egg was mixed with each sample. A strange reaction noted was that the DNA solution caused the hard-boiled egg to deteriorate before it was given to the planaria. The egg was then given to the appropriate member of the ERGs depending on which ECG planarian the genetic material was extracted from.

\section{Testing}

The egg was left in the ERG's water for two days before testing. They were conditioned with the same methods as the ECG. Once they displayed learning of the associative behavior by performing the conditioned response in three consecutive runs, their training was finished.

\section{Results}

The number of trials required to condition the ERG planaria was compared to the original ECG, the control group, to see if either of the treatments made a significant difference in the conditionability of the planaria. 
To prepare the data for analysis, the number of training events of each planaria was organized based on its group and aligned with its genetically identical counterparts (see Table 1).

Table 1. Number of trials required to condition each planarian. Each column contains the genetically identical counterpart planaria in each group.

\begin{tabular}{|c|c|c|c|c|c|c|c|c|c|c|c|}
\hline ECG & 15 & 30 & 28 & 21 & 15 & 22 & 10 & 29 & 27 & 36 & 11 \\
\hline RNA ERG & $-*$ & 12 & 11 & 14 & 9 & 18 & 13 & 16 & 18 & $-*$ & -* $^{*}$ \\
\hline DNA ERG & 29 & 9 & 11 & 20 & 19 & 10 & 9 & $-*$ & 18 & $-*$ & 25 \\
\hline
\end{tabular}

*There are blank spots in the table where the data from that planarian could not be used because it became unresponsive, or it was too underdeveloped to react to the CS.

The first test performed was a Kolmogorov-Smirnov test to see if the values were normally distributed (see Figure 3). All of the results from the different groups were analyzed together in this test.

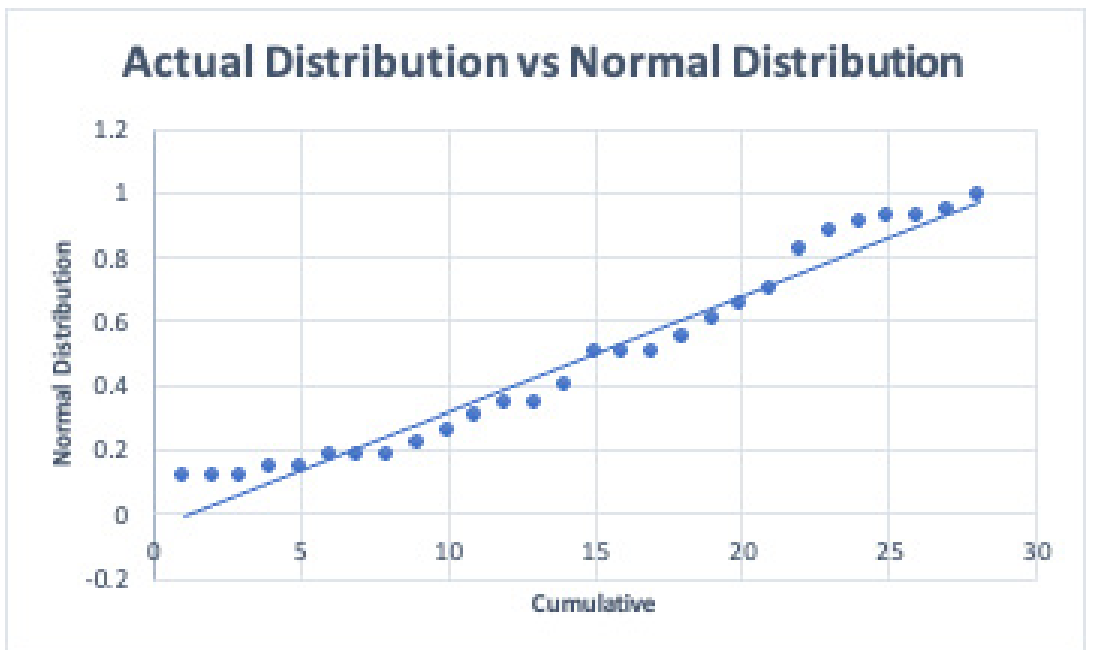

Figure 3. Actual Distribution vs Normal Distribution of Planaria Conditioning Trials. All of the individual planaria conditioning trials were combined and analyzed with a Kolmogorov-Smirnov test to determine whether they were normally distributed.

Since the data was normally distributed, a parametric test could be used. A parametric ANOVA one-way test was chosen to find any significant differences in the results of the three groups because an ANOVA test can compare several groups simultaneously with a multiple null hypothesis, and there was only one independent variable in this study: the type of genetic material received. The F-critical value (at 5\%) was 0.08 , which was less than the F calculated value, 3.47, showing that there were no significant variations in the number of conditioning trials among the three groups; therefore, neither the transfer of RNA nor DNA had a significant effect on the conditionability of the recipients. 


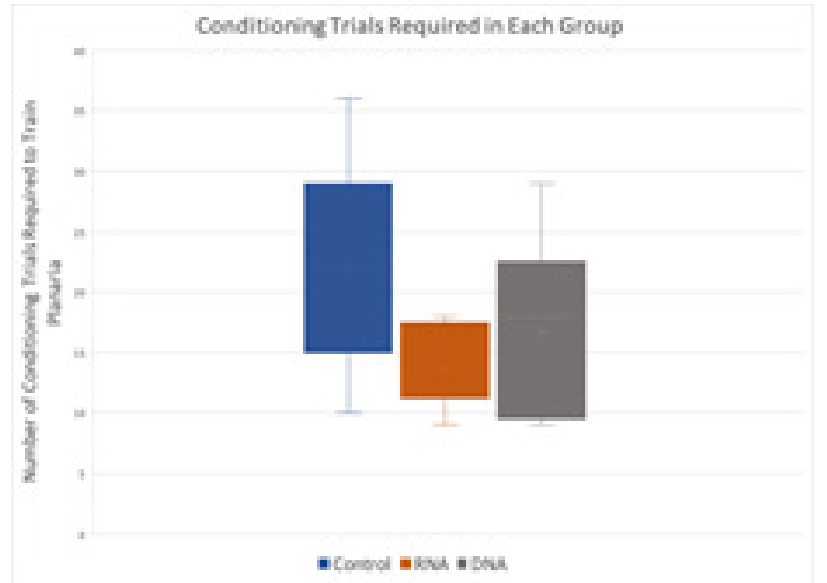

Figure 4. Conditioning Trials Required in Each Group. A box and whisker chart showing the number of conditioning trials for each planaria separated by experimental group.

\section{Discussion}

The hypothesis that the transfer of RNA or DNA from a conditioned planarian could increase the conditionability of the recipient was not supported by the results of this experiment since the data analysis showed no significant difference between the conditionability of planaria that had received RNA or DNA and naive planaria. However, procedural differences may be the reason the results of this experiment do not support the findings of some of the papers discussed in the introduction as well as similar memory experiments on Aplysia.

In Bédécarrats' et al. experiment on Aplysia, they found that the RNA from long-term sensitized Aplysia can induce sensitization (Bédécarrats et al., 2018). Unlike in their experiment, the ECG group in this experiment was conditioned only once and the DNA/RNA was extracted on the same day; they were not conditioned long-term. The difference between long-term and short-term sensitization may also have to do with Walker and Milton's finding that the number of shocks given to cannibalized flatworms was a positive function of the number of conditioned responses made by cannibal planaria (Walker \& Milton, 1966, p. 293). Therefore, long-term conditioning and, consequently, more shocks given to the ECG group may lead to increased sensitization to the training stimulus.

Assuming that RNA or DNA is able to alter the conditionability of recipients, the type and concentration of the genetic material may make a difference in the results. While it has been found that non-coding RNAs can mediate epigenetic modifications and that RNAi leads to selective suppression of individual gene functions, it is still unknown what specific part of genetic material is responsible for memory (Bédécarrats et al., 2018, p.1; Smalheiser et al., 2001, p. 216). RNAi can be induced by injecting double-stranded RNA into the body cavity in vivo, or by feeding animals bacteria that express exogenous RNAs, where, inside the cells, the double- RNA is cleaved into smaller protein-bound fragments that hybridize endogenous cellular sequences leading to selective degradation of endogenous mRNAs and suppression of individual gene functions (Smalheiser et al., 2001, p. 216).

The inhibitory effects on gene function are persistent throughout the lifespan of the planaria and become amplified over time, spreading to other regions of the body, including the germ line (Smalheiser et al., 2001, p. 216). However, RNAi has specific requirements which make it difficult to replicate experiments in RNA; for example, double stranded-RNA has a short lifetime in cells, and its ability to elicit RNAi requires a minimum sequence length, so any variations in the timing of extraction or the integrity of RNA preparations are crucial (Smalheiser et al., 2001, p. 216). An additional barrier in investigating the dynamics of memory at a molecular level in planaria is the difficulty of developing a robust learning assay because challenges include limited sample sizes, difficulty in precisely replicating protocol, and a lack of quantitative analysis (Shomrat \& Levin, 2013, p. 3800). 


\section{Conclusion}

Although the results of this experiment do not support the hypothesis that memory transfer through genetic material is possible, they do not disprove the possibility. Longer term sensitization of donor planaria as well as a more targeted transfer of genetic material may both magnify behavioral changes in recipients if present. Future research of genetic material like RNAi and non-coding RNA, as mentioned by Bédécarrats et al., 2018; Shomrat \& Levin, 2013; and Smalheiser et al., 2001, may be able to pinpoint the exact location of memory-bearing molecules, which would make the transfer of conditioned behavior more straight forward. Furthermore, it is possible that if the specific type of genetic material responsible for memory was isolated and amplified, it would lead to more pronounced results in the recipients, rather than if they received a portion of all-inclusive DNA or RNA. Importantly, an increased understanding of the neurological and genetic underpinnings of memory will have important implications in medicine as a whole, including stem-cell-derived treatments of degenerative brain disorders in humans and a broader understanding of the fundamental issues of the mechanisms of memory encoding and storage (Shomrat \& Levin, 2013, p. 3799, 3804).

\section{Acknowledgments}

I would like to thank Ms. Jessica Genter for giving me the opportunity to complete my research and experiment. Her help and guidance were vital to me in completing my project. I would also like to thank Dr. Allison Mayle from the DNA Learning Center for teaching me how to perform DNA and RNA extractions and supplying me with the necessary materials. Lastly, I would like to thank my classmates, especially Kristina Kaye and Mackenzie Murphy, for helping me with my experimental design and testing.

\section{References}

Abbot, S. M., \& Wong, G. K. (2008). The conditioning and memory retention of planaria (Dugesia tigrina) for directional preferences. BIOS, 79(4). https://doi.org/10.1893/0005-3155-79.4.160

Bédécarrats, A., Chen, S., Pearce, K., Cai, D., \& Glanzman, D. L. (2018). RNA from Trained Aplysia Can Induce an Epigenetic Engram for Long-Term Sensitization in Untrained Aplysia. eNeuro.

http://dx.doi.org/10.1523/ENEURO.0038-18.2018

Black Planaria (Dugesia dorotocephala), Culture, Class Size 30. (n.d.). Flinn Scientific. Retrieved May 7, 2020, from https://www.flinnsci.com/black-planaria-dugesia-dorotocephala-culture-class-size-30/lm1096/

Carney, R. S.E. (2018). An Emerging Role for RNA in a Memory-Like Behavioral Effect in Aplysia. ENeuro. https://doi.org/10.1523/ENEURO.0193-18.2018

Hawkins, R. D., \& Byrne, J. H. (2015). Associative Learning in Invertebrates. Cold Spring Harbor Laboratory Press. https://doi.org/10.1101/cshperspect.a021709

Mueller, C. T. (2002). The use of classical conditioning in planaria to investigate a non-neuronal memory mechanism. Research Science Institute. http://drmichaellevin.org/Planaria/prelimdata/CMueller.pdf

Ragland, R. S., \& Ragland, J. B. (1965). Planaria: Interspecific transfer of a conditionability factor through cannibalism. Psychonomic Science, 3(1-12), 117-118. https://doi.org/10.3758/BF03343051 
Shomrat, T., \& Levin, M. (2013). An automated training paradigm reveals long-term memory in planarians and its persistence through head regeneration. The Journal of Experimental Biology, 216, 3799-3810.

https://doi.org/10.1242/jeb.087809

Smalheiser, N. R., Manev, H., \& Costa, E. (2001). RNAi and brain function: Was McConnell on the right track?

Trends in Neurosciences, 24(4), 216-218. https://doi.org/10.1016/s0166-2236(00)01739-2

Walker, D. R. (1966). Memory transfer in planarians: An artifact of the experimental variables. Psychonomic Science, 5(9), 357-358. https://doi.org/10.3758/BF03328437

Walker, D. R., \& Milton, G. A. (1966). Memory transfer vs. sensitization in cannibal planarians. Psychonomic Science, 5(7), 293-294. https://doi.org/10.3758/BF03328401 